\title{
Dynamic Analysis of Test Frame of Railway Subgrade Dynamic Response Test System
}

\author{
http://dx.doi.org/10.3991/ijoe.v9iS7.3190 \\ Liangcai Zeng ${ }^{1}$, Feilong Zheng ${ }^{1}$, Anyu Zhang ${ }^{1}$, Gangsheng Kai ${ }^{2}$ \\ ${ }^{1}$ Wuhan University of Science and Technology, Wuhan, China \\ ${ }^{2}$ Equipment Department of WISCO, Wuhan, China
}

\begin{abstract}
In this paper, we take the railway subgrade dynamic response test system as the study object, the laboratory test reaction frame's model factors were analyzed through the finite element analysis software MSC.Patran/Nastran. The former six-order original frequencies and vibration modes of the frame were caculated and evaluated in detail. Then we studied its transient response under two working conditions: when it's fully loaded and suddenly unloaded, and the deformation displacement curves of the key points of the frame were obtained. These results provide a basis for the detailed study to the mechanical behavior of the frame and setting the proper working frequencies of the hydraulic servo excitation cylinder to avoid the resonance.
\end{abstract}

Index Terms-Frame, Dynamic analysis, Railway subgrade, Original frequency.

\section{INTRODUCTION}

Generally the light steel structures are mainly made of welded steel sheets or cold-formed steel members, which the typical light rigid structure is the portal frame [1]. As the steel portal frame are widely used, there are more and more new demands to the frames, such as higher antiseismic, greater stability, and longer fatigue resistance, etc [2].

A laboratory test device of the high speed railway subgrade dynamic response test system was set up in a university laboratory [3-5], and the core of which is the servo hydraulic excitation cylinder, its maximum excitation force is $300 \mathrm{kN}$ and the maximum excitation frequency is $40 \mathrm{~Hz}$. In order to avoid resonance, prevent the servo hydraulic cylinder and the frame from being destructed, it is need to take the dynamic analysis to the frame to find out its natural frequencies and study the dynamic response under the typical work conditions, which may be help to set a reasonable frequency range of the servo hydraulic excitation cylinder and provide a basis for the later dynamic design.

\section{FINITE ELEMENT MODEL OF THE FRAME}

Compared with the ordinary cast structure, welded structures has the advantages of high strength and rigidity, light weight, short productive cycle and easy to construct, so we choose the welded assembly frame. Fig. 1 shows the laboratory test frame of the high-speed railway dynamic response excitation test system, which is mainly composed of the base, columns, beam and connection plate.

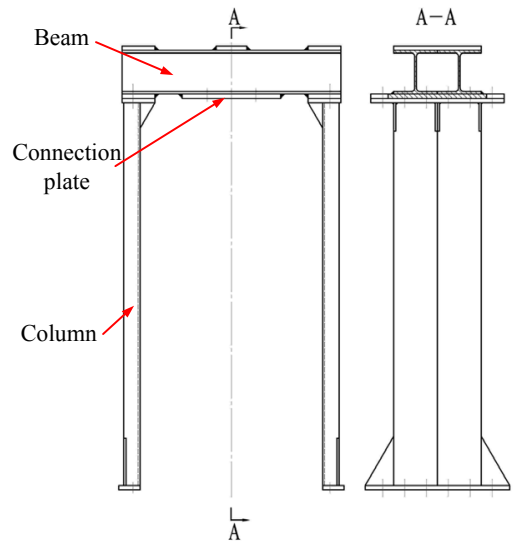

Figure 1. Structure of the frame

The base is the T-slot cast iron foundation (not appeared in Fig. 1).

The columns are respectively welded of two U-bars. The bottoms of them are bolted to the base.

The beam is made of two H-beam that welded together. The top and bottom of it are welded some strengthen plate. The beam is bolted symmetrically to the top of the columns.

The connection plate is of round shape and its upper surface is welded under the beam and the lower surface can mount the servo excitation cylinder through the screws.

The structure of the frame is complex, so its threedimensional solid model is created in a graphics software firstly, and then import it to the MSC.Patran software [6]. The beam, column and base are connected with highstrength bolts that can be considered as the fixed connection. Considering each element must be continuous, so different solid elements should be meshed probably. Finite meshing adopts 10 nodes Tet element, and the frame is meshed into 73494 elements and 138201 nodes. The modulus of elasticity is set as $203 \mathrm{GPa}$, Poisson's ratioto is 0.3 , the density is $7.8 \times 10^{3} \mathrm{~kg} / \mathrm{m}^{3}$.

\section{THE FRAME MODAL ANALYSIS}

\section{A. Modal Analysis Theory}

Modal analysis is the modern approach to study the dynamic characteristics of the structure [7]; it can be used to study the natural vibration performance of the mechanical structure. Each mode has a specific natural frequency, damping ratio and mode shapes [8]. When we study the natural frequencies and mode shapes of the reaction bracket, its damping can be ignored. As the 
external load is zero, the system dynamic equations can be expressed as:

$$
[M]\{\ddot{x}\}+[K]\{x\}=0
$$

Where $[M]$ is the mass matrix, $\{\ddot{x}\}$ is the acceleration vector; $[K]$ is the stiffness matrix; $\{x\}$ is the displacement vector.

Its solution is:

$$
\{x\}=\{\phi\} e^{i a x}
$$

So the characteristic equation will be:

$$
\left([K]-\omega^{2}[M]\right)\{\phi\}=0
$$

Where $\omega$ is the natural frequency of the system.

For the equation above, MSC.NASTRAN provides three types of solution: tracking method, changes method and the Lanczos method. They have their own advantages, comparatively speaking, Lanczos method could solve the very large eigenvalue problem, doesn't lose the roots, allows the singular mass matrix, and can get more feature values, so it is recommended.

\section{B. Analysis and Discuss}

After being computed in MSC.Nastran, the former sixorder natural frequencies and the amplitudes of the reaction frame are shown in Table 1.

It can be seen from Table 1, the first order natural frequency of the reaction frame is low and under the working frequency; the second and third order natural frequencies are slightly larger than the servo excitation cylinder maximum operating frequency. Totally, the amplitude of each vibration mode shows that bottom of the columns where joint with the base and the beam are almost not distorted, however the amplitude of the columns is much greater, ranges from 0.06 to $0.19 \mathrm{~m}$. The former six order modal vibration modes are shown in Fig. 2.

TABLE I.

FORMER SIX-ORDER NATURAL FREQUENCIES AND AMPLITUDE OF THE REACTION FRAME

\begin{tabular}{|c|c|c|}
\hline Order & Natural Frequency (Hz) & Amplitude (m) \\
\hline 1 & 15.56 & $5.92 \times 10^{-2}$ \\
\hline 2 & 42.85 & $7.16 \times 10^{-2}$ \\
\hline 3 & 55.49 & $9.67 \times 10^{-2}$ \\
\hline 4 & 119.46 & $1.21 \times 10^{-1}$ \\
\hline 5 & 128.10 & $1.20 \times 10^{-1}$ \\
\hline 6 & 136.28 & $1.94 \times 10^{-1}$ \\
\hline
\end{tabular}

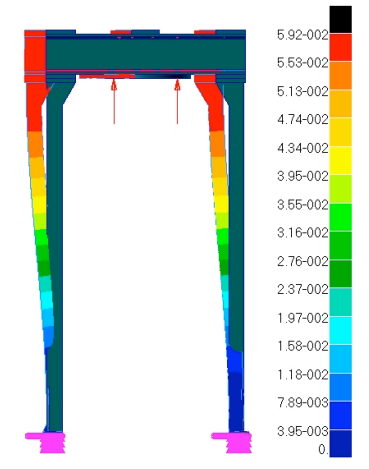

(1) The first-order modal

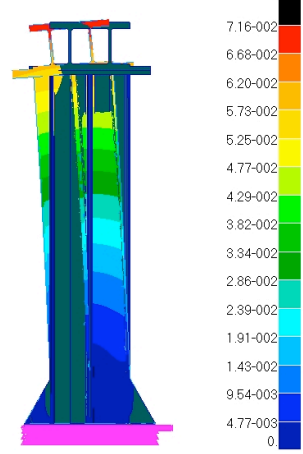

(2) The second-order modal

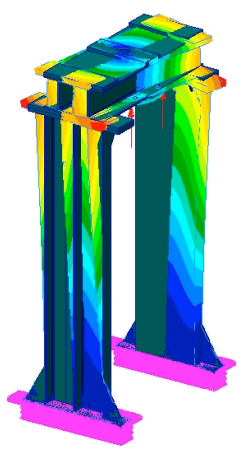

(3) The third-order modal

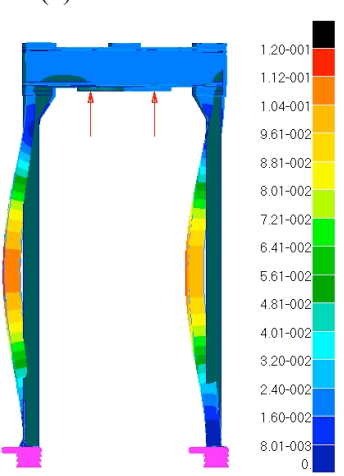

(5) The fifth-order modal

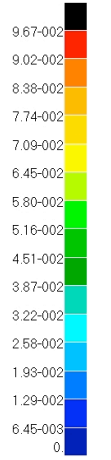

(5) The fifth-order modal

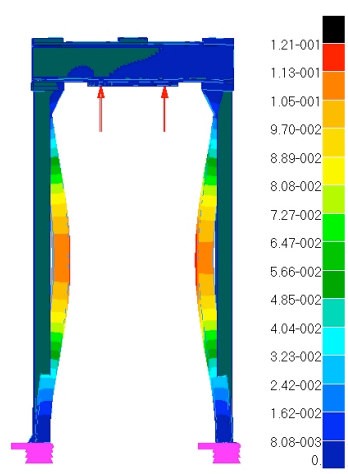

(4) The fourth-order modal

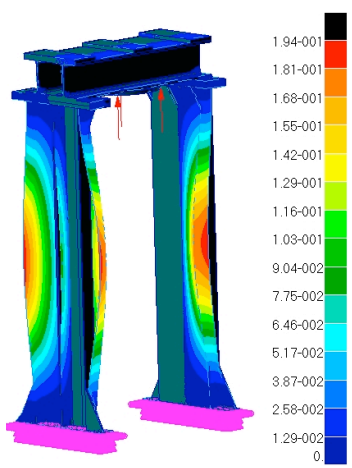

(6) The sixth-order modal
Figure 2. The former six-order vibration modes of the reaction frame

The modal analysis shows that:

1) The stiffness of the column is relatively small; the former three order frequencies impact it obviously;

2) The first-three-order natural frequencies- $15.56 \mathrm{~Hz}$, $42.85 \mathrm{~Hz}$ and $55.49 \mathrm{~Hz}$ - are more sensitive to the load, they produce the swing and twist deformation in frontback and left-right direction;

3) The fourth, fifth and sixth vibration modes are lateral deformation and twist at the central of the column;

4) From the pictures, the frame may not only occur the bend deformation in front-back and left-right direction, but also the torsional deformation. It probably affects the strength and rigidity of the frame, raises the bolt stress, influences the output precision of the excitation hydraulic cylinders, aggravates the wear of moving parts of the servo hydraulic cylinders and reduces the cylinder and the frame's life. Therefore, in the future design it is necessary to increase the local stiffness and damping appropriately to suppress the vibration;

5) The distribution of the overall integral stiffness and mass is comparatively balanced, there is no noticeably weakness and excess, it will help to improve the dynamic characteristics of the frame.

\section{THE FRAME TRANSIENT RESPONSE ANALYSIS}

The transient dynamic analysis (also known as timehistory analysis) is used to analyze the response of the structure under time dependent load, including the static load, transient load or any combination of them [9-10].

In Nastran, there are two approaches to study transient response: direct and modal method. The direct method is of high precision, so it is chosen in this paper. Fig. 3 is the boundary condition of the transient analysis, Fig. 4 is the input stress-loading curve in $40 \mathrm{~Hz}$. In the picture, the sine- 
wave curve in $0 \sim 0.08125 \mathrm{~s}$ represents $31 / 3$ cycles' excitation, and it inspects the response of the frame under the forced vibration; the after till $0.3 \mathrm{~s}$ represents the unloaded state, it is used to study the response of the frame as it unloads suddenly.

Fig. 5 is the displacement curve in the Y-direction of the element 1 at the top of the beam. It shows that at the beginning, a slight vibration is occurred, and then it is relatively stable, the amplitude is about $4.4 \mathrm{~mm}$; as unloaded, there is a slight concussion, ranging about $1 \mathrm{~mm}$, but soon it becomes static. Fig. 6 presents the displacement curve in the Z-direction of the element 2 inside the column. At first it is in an irregular shape that within an approximately sinusoidal trend. The vibration amplitude is small, the maximum is about $0.36 \mathrm{~mm}$; there is a slight concussion after unloading, and the maximum amplitude is about $0.24 \mathrm{~mm}$.

\section{CONCLUSIONS}

In this paper, the dynamic response of the laboratory test frame of the high speed railway subgrade test system has been studied through the FEA software MSC.Patran/Nastran, and we can safely come to the conclusions:

1) The operation frequency range of the hydraulic excitation cylinder is of $0 \sim 40 \mathrm{~Hz}$, that may cover or approach the first two order natural frequencies of the frame and may resonate easily. To avoid this, it is recommended to set the excitation frequency band to $0 \sim$ $15 \mathrm{~Hz}$ and $16 \sim 38 \mathrm{~Hz}$;

2) If the excitation frequency is exactly close to the first or second order natural frequency of the rack, it is required to enhance the rack's structural rigidity, so that it is greater than $40 \mathrm{~Hz}$ to avoid the occurrence of resonance.

3) Under the conditions of the maximum force and frequency is applied and suddenly unload, the maximum displacements of the rack are all within the allowed limits, and the design is reasonable.

\section{ACKNOWLEDGMENT}

The authors would like to offer their gratitude to the National Natural Science Foundation of China for their financial support. The Grant nos. 51027002, 51175386, and 51175388.

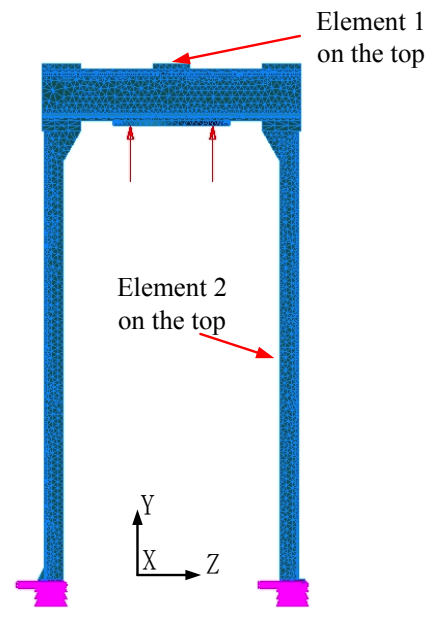

Figure 3. Boundary condition

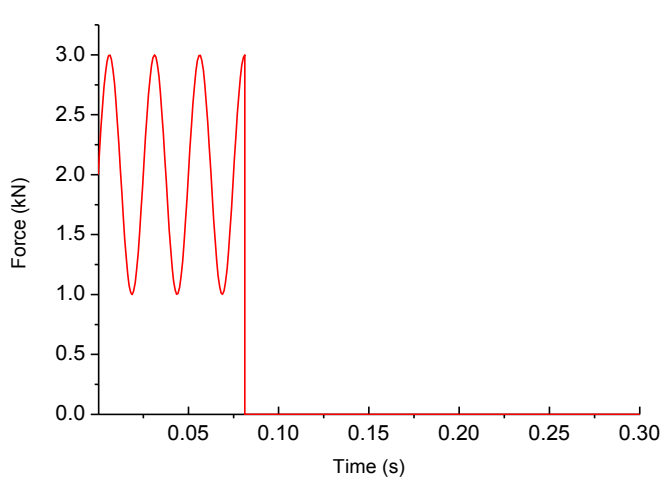

Figure 4. Input stress-loading curve

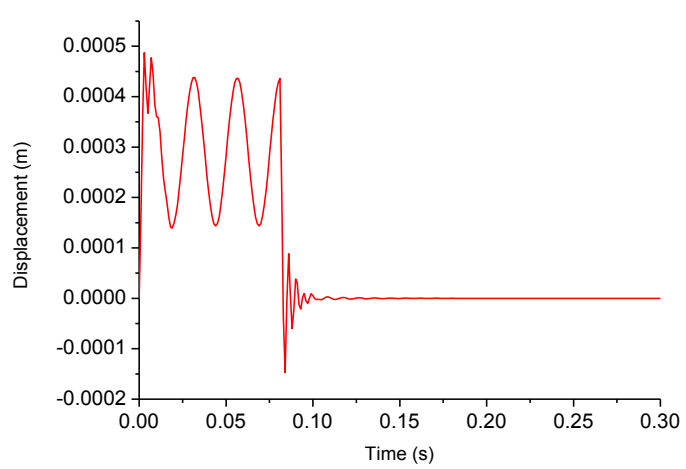

Figure 5. Time-displacement curves of element 1

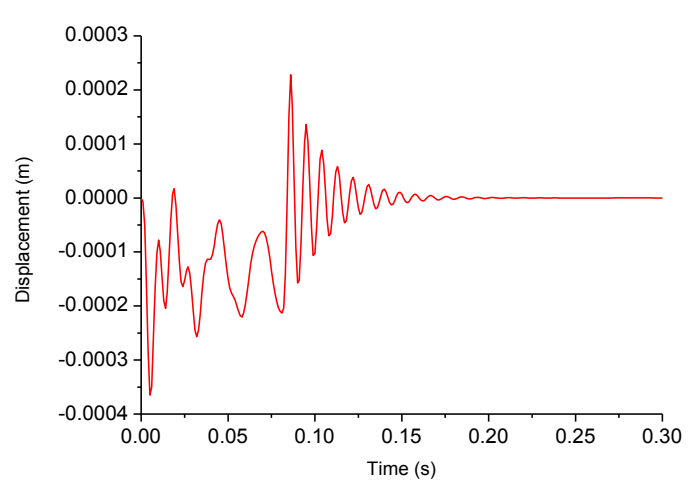

Figure 6. Time-displacement curves of element 2

\section{REFERENCES}

[1] A.H. Zubydan, "Inelastic second order analysis of steel frame elements flexed about minor axis," Engineering Structures, vol. 33, pp. 1125-1240, 2011. http://dx.doi.org/10.1016/j.engstruct. 2010.12.046

[2] Y. Hou, D. Huo, H. Teng, and Y. Zhang, "Analysis of strength reliability of semi-rigid steel frame," Beijing Gongye Daxue Xuebao/Journal of Beijing UNI, vol. 36, pp. 1477-1481, 2010.

[3] F. L. Zheng, L. C. Zeng, G. S. Kai, C. Yu, and Q. H. Xi, "The simulation and optimization of the electro-hydraulic proportional control system based on Simulink/SRO," Sensors and Transducers, vol. 21, SPEC.ISS.5, pp. 1 - 7, 2013.

[4] L. C. Zeng, F. L. Zheng, Y. Wan, and Q. H. Xi, "Hydraulic system design and simulation of high-speed railway dynamic test system excitation device," Applied Mechanics and Materials. PART 1, vol. 271, pp.953-957 [3rd International Conference on Frontiers of Manufacturing and Design Science, ICFMD 2012]. 
[5] F. L. Zheng, L. C. Zeng and X. Y. Chen, "Simulation on following performance of high-speed railway in situ testing system," Advances in Mechanical Engineering, vol. 2013, 2013.

[6] S. Hwan, H. Woo, L. Ryong, and L. Moon, "Structural stability estimation of whirling unit," Transactions of Nonferrous Metals Society of China, vol. 19, pp. 202-208, 2009. http://dx.doi.org/10.1016/S1003-6326(10)60271-3

[7] L. Renson, J. P. Noel, G. Kerschen, and A. Newerla, "Nonlinear modal analysis of the SmallSat spacecraft," European Space Agency, (Special Publication) ESA S, vol. 691 SP, 2012.

[8] R. Zeinali davarani, R. Ghazi, and N. Pariz, "Nonlinear modal analysis of interaction between torsional modes and SVC controllers," Electric Power Systems Research, vol. 91, pp. 61-70, 2012. http://dx.doi.org/10.1016/j.epsr.2012.04.017

[9] S. Takahashi, K. Muramatsu, and A. Kimoto, "3D transient analysis of ultrasound propagation using finite difference time domain method and its experimental verification," Proceedings IEEE Ultrasonics Symposium, pp.2295-2298, October 2007 [2007 IEEE Ultrasonics Symposium Proceedings, IUS].

[10] F. Qanbari, and C.R. Clarkson, "Rate transient analysis of stresssensitive formations during transient linear flow period," Society of Petroleum Engineers - SPE Canadian UNCO, vol. 2, pp. 1107 $1111,2012$.

\section{AUTHORS}

Liangcai Zeng received the Ph.D. degree in mechanical design and theory from Wuhan University of Technology, China in 2005. Currently, he is the dean of school of machinery and automation in Wuhan University of Science and Technology, China. His research interests include monitoring and fault diagnosis in hydraulic equipments and control of electric-hydraulic serve system.

Feilong Zheng received the Bachelor's degree in mechanical design, manufacturing and automation from Hubei University of Technology, China in 2008. Currently, he is a reading his doctorate at Wuhan University of Science and Technology, China. His research interests include design and control of hydraulic servo system and fault diagnosis.

Anyu Zhang was born in Hubei province, P. R. China, in 1989. He received B.S. degree in mechanical engineering and automation from Wuhan University of Science and Technology, Wuhan, China, in 2011. He is currently occupied in his M.S. degree in hydraulic transmission and control at Wuhan University of Science and Technology, College of Machinery and Automation. His current research interests include hydraulic servo system control and fault diagnose.

Gangsheng Kai received the Master's degree in automation from Huazhong University of Science and Technology, China. Currently, he is working in equipment department of WISCO, China. His research interests include control in electrical automation system.

Submitted, 16 September 2013. Published as resubmitted by the authors on 12 October 2013. 